\title{
Bir Karaçam Kökünün Anatomisi: Heyelan İzleri*
}

\author{
Barbaros YAMAN \\ Bartın Üniversitesi, Orman Fakültesi \\ Yıllık Halka Analizleri ve Odun Anatomisi Laboratuvarı, Bartın/Türkiye \\ yamanbar@gmail.com
}

Özet: Yıllık halka tarihlendirme bilimi olarak dendrokronoloji, fiziksel çevre ve kültürel alanlarda zamansal ve mekânsal süreçlerin analiz edilmesinde yanılma payı oldukça düşük olan ve yıllık çözünürlükte bilgi sunan önemli bir araç olarak kabul edilmektedir. Bu bilim dalının jeomorfolojik olay ve olgularla ilişkili alt dalına da dendrojeomorfoloji adı verilmiştir. Jeomorfolojik olay yeri ve yakın çevresinde bulunan ağaç ve diğer odunsu bitkilerde gerçekleştirilen yıllık halka analizleri, jeomorfolojinin birçok alanı için aydınlatıcı bilgi sunabilmektedir. Oluşum tarihleri bilinmeyen heyelanlar başta olmak üzere, kaya ve taş yuvarlanmaları, enkaz ve çamur akışları, ani seller, çığlar, toprak erozyonu ve kumul hareketleri gibi fiziki coğrafyayı ilgilendiren birçok olgunun yaşlandırılmasında, ilgili jeomorfolojik olaydan etkilenen ve zarar gören ağaçların yıllık halka kronolojileri ve yıllık halka anatomisine ilişkin bilgiler kullanılmaktadır. Bu makalede Bartın Akörensöküler Köyü'nde 2012 yılında meydana gelen heyelan sahasında bulunan bir karaçamın açığa çıkan kökü anatomik yönden incelenmiştir. Heyelan sonrası dönemde yıllık halka genişlikleri ile birlikte yaz odunu genişliği de artmış, ancak traheid çapları ortalama $\% 45$ oranında azalmıştır. Bu sonuçlar ilgili referanslar temelinde beklenen sonuçlardır. Bununla birlikte açığa çıkan kökte heyelanla oluşmuş mikro-yaraların tetiklediği dişli yıllık halkalar da (indented rings) olay zamanına işaret etmektedir.

Anahtar kelimeler: Dendrojeomorfoloji, heyelan, kök odunu anatomisi, Pinus nigra

\section{Root Wood Anatomy of a Black Pine Tree: Landslide Traces}

Abstract: Dendrochronology is the scientific discipline of dating based on tree-rings (growth rings) to analyse temporal and spatial patterns of processes in the physical and cultural sciences. Of which a subdiscipline of dendrochronology, dendrogeomorhology provides the techniques to date and analyse earth surface processes such as rockfall and landslide events, debris and mood flows, flash floods, avalanches, erosion and sand dune dynamics, and etc. Moreover, exposed-root anatomy has been recently used for dendrogeomorphological studies. In this study, found in a small scale landslide event happened in the year of 2012 in Akörensöküler, Bartın - Turkey, the exposed root wood of a black pine tree was investigated anatomically. After the event, albeit wider tree rings with large latewood were formed, tracheid diameters were $45 \%$ smaller. These are expected results on the basis of former dendrogeomorphological studies. However, indented rings formed due to micro-scars in the exposed root also indicated to the event time.

Keywords: Dendrogeomorphology, landslide, root wood anatomy, Pinus nigra

\section{Giriş}

Jeomorfoloji çalışmalarında yaşlandırma yöntemleri arasında dendrokronoloji ve ksiloloji de yer almaktadır. Yıllık halka tarihlendirme bilimi olarak dendrokronoloji (dendro odun, chronos zaman, logos bilim), doğal süreçlerin ve insanla ilgili birçok tarihsel olayın aydınlatılmasinda, yanılma payı oldukça düşük olan ve yıllık çözünürlükte veri sunan önemli bir araç olarak kabul edilmektedir (Schweingruber, 1989; Akkemik, 2004). Yeryüzünün şekillenmesinde rolü olan belli başlı etken ve süreçlerin, odunsu bitkilerin y1llık halkalarının kullanılarak tarihlendirilmesi bu bilim dalının dendrojeomorfoloji adı verilen alt dalını oluşturur (Schweingruber, 1989; Akkemik, 2004; Avc1, 2007).

Genel olarak "süreç-olay-tepki" temeline dayanan dendrojeomorfoloji araştırmaları, buzul hareketleri, volkan patlamaları, depremler, enkaz (döküntü) akışları, kaya düşmeleri, heyelanlar, çı̆̆lar, kumul hareketleri, erozyon, ani su baskınları ve seller gibi konu başlıklarını kapsar (Avcı, 2007). Dendrojeomorfolojinin heyelanlarla ilgili alanında çeşitli yöntemler kullanılmaktadır (Wilford ve ark., 2005). Örneğin bir heyelan deposu üzerinde yetişmiş en yaşlı odunsu bitkilerde minimum yaş tespitleri yapilarak, heyelan sonrası geçen zamanın tahmin edilmesi bunlardan birisidir (Butler ve ark., 
1987; Clague, 2010). Diğer bir yaklaşım heyelandan zarar gören canlı odunsu bitkilerin yıllık halka özelliklerinin incelenmesidir. Heyelan esnasında odunsu bitkilerin taç ya da kök sistemlerinde meydana gelen zararlar yıllık halkaların daralmasina neden olmaktadır. Bazen de rekabet halindeki odunsu bitkilerden bir ya da birkaçı heyelan nedeniyle ortamdan çekildiği için kalan bireylerde halka genişlikleri artabilmektedir. Diğer taraftan heyelan esnasinda alan üzerinde bulunan odunsu bitkilerden bazıları (özellikle ağaçlar) belirli yönlere doğru eğilebilmektedir. Eğilen ağaçlarda, pozitif fototropizm ve negatif jeotropizm etkisi altında, gövde doğrulmaya zorlanırken reaksiyon odunu oluşur (Gymnospermlerde basınç odunu, Angiospermlerde çekme odunu). Her iki durumda da eğilen ve reaksiyon odunu oluşmaya başlayan bir gövdede y1llı halkalar reaksiyon odunu tarafında daha geniş olur (eksantrik gövde) ve ilerleyen yıllarda öz gövdenin bir tarafina kaymış gibi görünür (Schweingruber, 1989; Schweingruber, 2007). Bu tür eksantrik gövdelerde son oluşan yıllık halkadan geriye doğru yıllık halkaların "eksantriklik indeksi" hesaplanarak heyelan yaşlandırması yapilabilmektedir (Schweingruber, 2007; Wistuba ve ark., 2011; Malik ve Wistuba, 2012). Bazen de heyelan alanında bazı odunsu bitkiler tamamen ölebilir. Aynı türden odunsu bitkilerin ana kronolojileri ile eşleştirme yapılarak bu tür bireylerin ölüm tarihleri belirlenebilmektedir (Clague, 2010).

Heyelan alanlarında dikkati çeken ve yaşlandırmada çok önemli yeri olan diğer bir yöntem de bazı odunsu bitkilerin (özellikle heyelan kenarındaki ağaçların) heyelan nedeniyle açığa çıkan köklerinin incelenmesidir (Gaertner ve ark., 2001; Gaertner, 2007; Schweingruber, 2007; Stoffel ve Bollschweiller, 2009). Açığa çıkan köklerden ucu tamamen toprak dışına çıkmış veya toprak ile bağlantısı kopmuş olanlar heyelan sonrası ölmektedir. Bu tür köklerde ölüm yılı belirlenebilir. Uç kısımları toprak içinde olan ancak bir kısmı açığa çıkmış olan kökler canlı köklerdir. Bu tür kökler heyelan sonrasında da büyümeye ve vasküler kambiyum faaliyetiyle kalınlaşmaya devam etmektedir. Böyle köklerde açığa çıkmış kısımdan alınan odun kesitlerinde heyelan öncesi ile heyelan sonrasi oluşan kök odunu anatomik yönden farklı olmaktadır (Schweingruber, 2007; Gaertner, 2007; Stoffel ve Bollschweiller, 2009). Heyelan öncesi ve heyelan sonrası yıllık halkalardaki bu anatomik farklılıklar heyelanların yaşlandırılmasını sağlamaktadır. Ayrıca heyelan nedeniyle yara izi bulunan gövde veya kök kısımlarındaki kallus da (yara dokusu) heyelana işaret edebilmektedir (Schweingruber, 2007; Stoffel ve Bollschweiller, 2009).

Heyelanlar, birçok ülkede insan yaşamını doğrudan etkileyen en önemli doğal afetlerden birisidir. EM-DAT (Uluslararas1 Afet Veri Bankası) verilerine göre 1976-2015 döneminde Türkiye'de meydana gelen heyelanlardan binlerce yurttaş etkilenmiş, dört yüzün üzerinde kişi söz konusu heyelanlarda yaşamını yitirmiştir (EM-DAT, 2016). Heyelanlar, Türkiye'nin hemen hemen her bölgesinde meydana gelebilen jeomorfolojik bir olgu olmasına rağmen, Karadeniz Bölgesi dağlı bir topoğrafyaya sahip olması, bol yağış alması ve Kuzey Anadolu Fay Hattına (KAF) yakın olması nedeniyle heyelana daha duyarlı bir bölgedir (Ercanoğlu ve ark., 2004; Ercanoğlu, 2005). Karadeniz Bölgesi'nde akıllarda kalan en önemli heyelanlardan birisi 23 Haziran 1988 tarihinde Trabzon Çatak'ta gerçekleşen ve 64 kişinin ölümü ile sonuçlanan heyelandır (EMDAT, 2016).

Türkiye ölümlü heyelanlara maruz kalan bir ülke olmasına rağmen jeomorfoloji alanında ağaç yıllık halka analizleri temelinde gerçekleştirilen çalışmaların sayısı yok denecek kadar azdır. Bu alanda ülkemizde gerçekleştirilmiş çalışmalardan en önemlisi bir heyelan gölü olan Sülük Gölü'nün olușum zamanının yaşlandırılmasıdır (Aytuğ, 1984; Aytŭ̆ ve Kılıç, 1993). Son y1llarda Türkiye'de heyelan-yıllık halka ilişkisi üzerine yapılan çalışmalara Pınarcı ve Çetin (2012) ile Yaman ve ark. (2013)'nın araştırmaları örnek olarak verilebilir. $\mathrm{Bu}$ çalışmalarda heyelandan etkilenen ağaçlarda Pınarc1 ve Çetin (2012) sadece gövde odunu kronolojisini, Yaman ve ark. (2013) ise hem gövde odunu hem de kök odunu kronolojisi ve anatomisini kullanmışlardır. $\mathrm{Bu}$ bağlamda çalışmanın amacı, Bartın'da oluşum tarihi bilinen bir heyelan sahasında (Akörensöküler 
Köyü, Ulus, Bartın, Mart 2012) bulunan bir karaçam ağacının köklerinde heyelan öncesi / sonrası yıllık halka gelişim seyrinin ve yıllık halka anatomisinin incelenmesi ve konu ile ilgili bazı çıkarımlarda bulunulmasıdır.

\section{Materyal ve Metot}

Bartın-Ulus ilçesi Akörensöküler Köyü'nde 23 Mart 2012 tarihinde bir ailenin evinin ve müştemilatının yıkılmasına neden olan bir heyelan meydana gelmiştir. Heyelan esnasında köklerinin bir kısmı açığa çıkmış bir karaçam bireyinin kök odunu bu araştırmanın materyalini oluşturmuştur (Şekil 1 ve 2). Köklerden birisi toprakla bağlantısı kopmuş olan ölü, diğeri ise toprakla bağlantısı devam eden, üzerinde kısmi yara izi bulunan fonksiyonel ve canlı köktür. Açığa çıkmış canlı kökten (çatal) el testeresiyle kesilen 50 $\mathrm{cm}$ boyundaki odun parçası Bartın Üniversitesi Orman Fakültesi Odun Anatomisi ve Dendrokronoloji Laboratuvarı'na transfer edilmiștir. Burada motorlu kıl testeresi ile köklerden, enine yüzey boyuna eksene tam dik olacak şekilde ve yaklaşık $1 \mathrm{~cm}$ kalınlığında, tekerlekler kesilmiştir. Yıllık halkaları belirginleştirmek amaciyla, tekerlekler su ile kaynatılıp yumuşatıldıktan sonra, enine yüzeyler mikrotom bıçağ ile düzleştirilmiş ve ardından stereo-mikroskop altında fotoğraflanmıştır

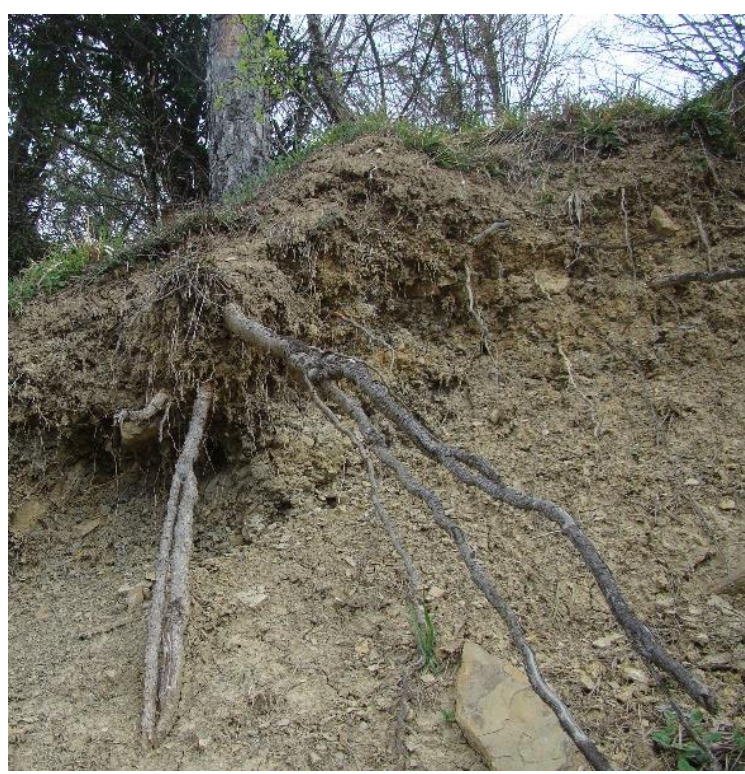

Şekil 1. Açığa çıkan kökler.
(Şekil 3). Heyelan sonras1 döneme ait (2012 y1lı dâhil) yıllık halka genişlikleri hazırlanan bu tekerlekler üzerinde $0,01 \mathrm{~mm}$ duyarlılıkla ölçülmüştür. Dar oldukları için makroskobik kesitte görülemeyen heyelan öncesi döneme ait yıllık halkaların genişlikleri ise mikrotomla alınan mikroskobik kesitler üzerinde ölçülmüştür (Şekil $5 \mathrm{a}$ ve b). Yillık halka genişliklerinin yıllara bağlı değişimi Şekil 4'de bir grafikle gösterilmiştir.

İncelemeye konu olan kökün anatomisi (2008-2015), heyelanın olduğu 2012 yılını da içerecek şekilde, mikrotomla alınan $20 \mu \mathrm{m}$ kalınlığındaki enine kesitler üzerinde incelenmiştir. Kesitler safranin+astra blue karışımı ile boyandıktan sonra sıvı gliserin kullanılarak lam-lamel arasında geçici görüle olarak hazırlanmış ve traheid radyal çapı ölçümleri Olympus-CX21 1ş1k mikroskobunda gerçekleştirilmiştir. Traheid radyal çap1 ölçümlerinde yıllık halkaların ilkbahar odununda ilk üç-dört sıra traheid esas alınmış ve incelenen her bir y1llık halkada, ortalama traheid çapı için, 20 farklı traheid değerlendirilmiştir. Elde edilen ortalama değerler üzerinden grafik çizilmiştir (Şekil 6). Bütün bu işlemlerde ve anatomi ile ilgili kullanılan terminolojide IAWA Committe (2004) ile Gaertner ve Schweingruber (2013) esas alınmıştır.

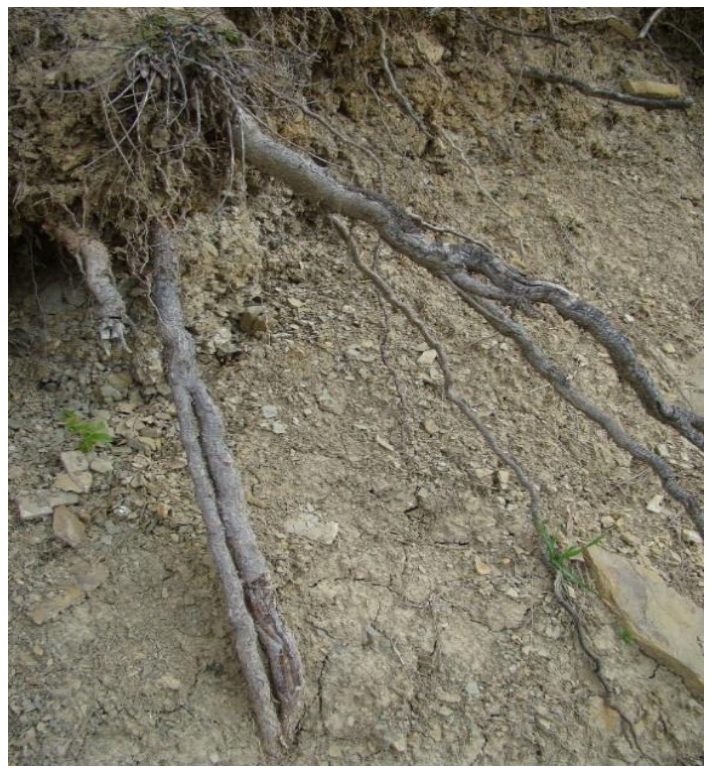

Şekil 2. Köklerin yakından görünümü. 


\section{Bulgular}

23 Mart 2012 tarihinde meydana gelen heyelandan odun numunelerinin alındığ 11 Mart 2016 tarihine kadar dört vejetasyon dönemi geçmiştir. Arazi çalışmasının yapıldığı tarih itibariyle incelenen karaçamın gövdesinde ve kökün açığa çıkmış kısımlarında 2016 y1lı için henüz yıllık yıllık halka oluşumunun başlamadığı tespit edilmiştir. Dolayısıyla incelenen kök odununda oluşumunu tamamlamış en son y1llık halka (ilkbahar odunu + yaz odunu) 2015 yılina aittir.

Heyelan 2012 y1lı vejetasyon dönemi başlamadan meydana geldiği için heyelanın akabindeki aylarda (nisan veya mayıs) oluşmaya başlayan ve vejetasyon dönemi sonunda oluşumu tamamlanan 2012 y1li halkası da 2013, 2014 ve 2015 yıllarına ait halkalar gibi geniş olarak oluşmuştur. Heyelanın olduğu yıl dahil son dört yıllık halka makroskopik kesitte net olarak görülmektedir (Şekil 3). Şekil 3'teki kök makro enine kesitinde görülemeyen mikro- yara izleri ise şekil 7'deki mikro kesitlerde izlenmektedir. Heyelan esnasında yaralanan bu kısımda heyelan sonrası dönemde oluşan dişli yıllık halkalardan heyelanın gerçekleştiği zamanı görsel olarak tespit etmek mümkündür.

Şekil 3'de gösterilen kök enine yüzeyinde son dört y1la ait (2012-2015) ortalama y1ll1k halka genişliği $1.63 \pm 0.14 \mathrm{~mm}$ olarak hesaplanmıştır. Mikroskobik enine kesitler üzerinde heyelan öncesindeki (2008-2011) ortalama y1llık halka genişliği ise $0.52 \pm 0.13$ mm olarak belirlenmiştir. 2008 yılından 2015 yılına kadar son 8 y1llık dönemdeki yıllık halka genişliği değiş̧imi Şekil 4'deki grafikte gösterilmiştir. Böylece incelenen kök sektöründe heyelan sonrası ortalama y1llık halka genişliğinin $\% 300 \quad$ arttığ anlaşılmaktadır. Ayrıca, yıllık halkalarda heyelan öncesi dönemde yaz odunu zonu çok dar iken (genellikle 1-3 traheid sirası), heyelan sonrası dönemde yaz odunu zonu genişliği artmıştır.

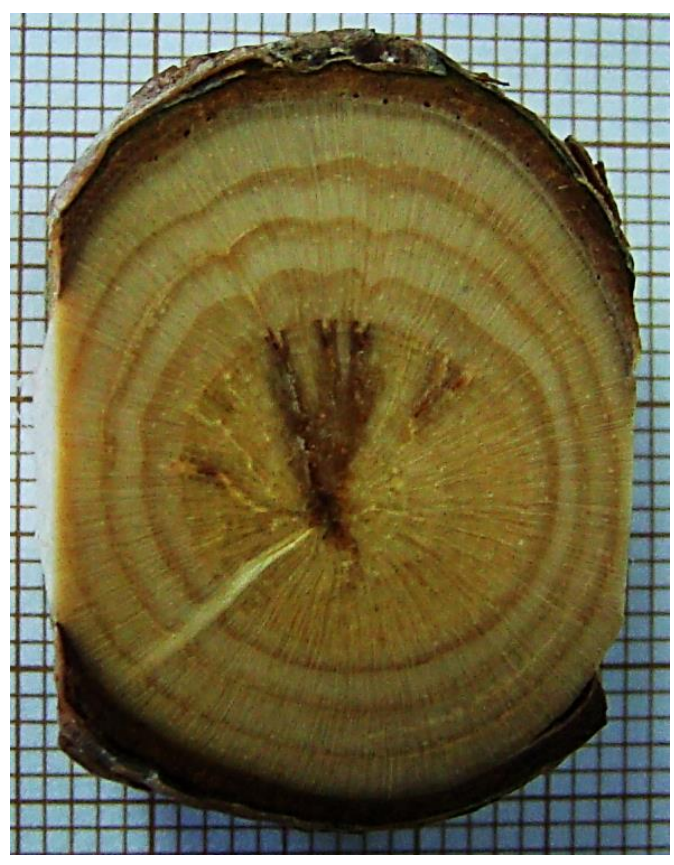

Şekil 3. Heyelan nedeniyle açığa çıkan kök odunun makro enine kesiti. 


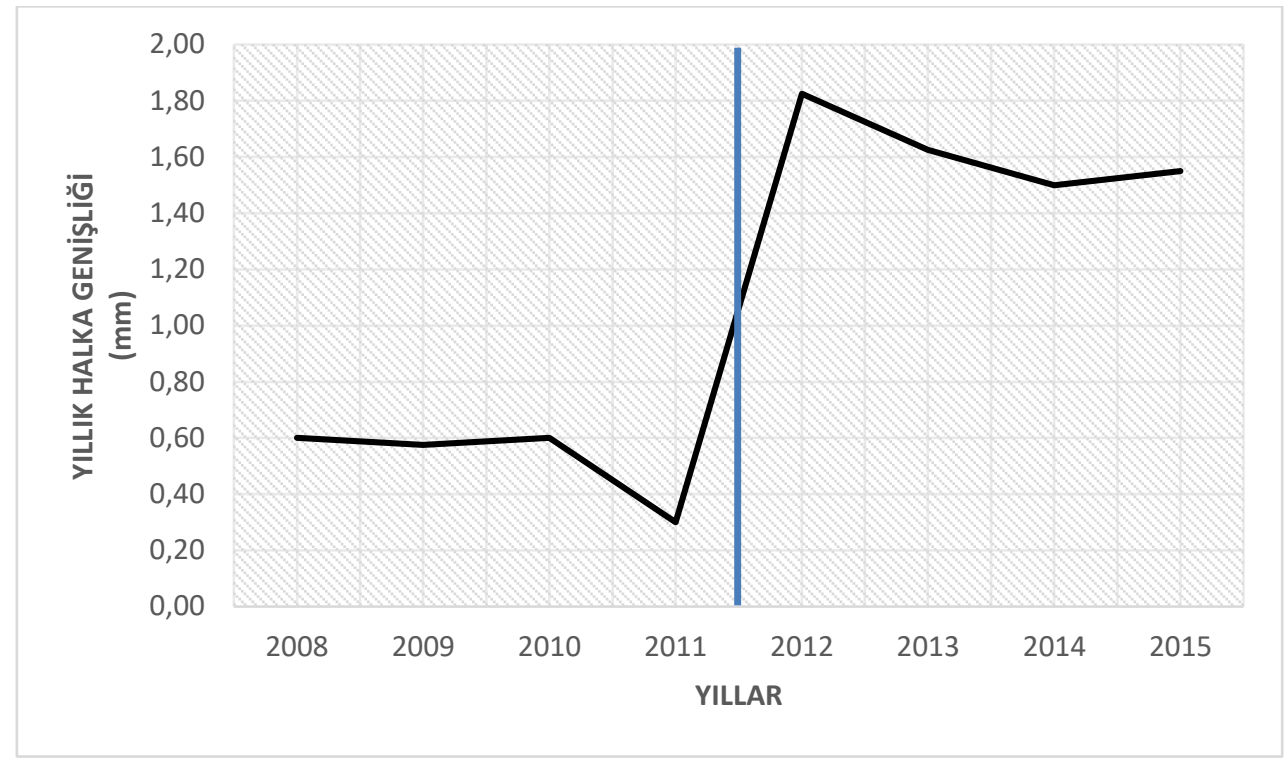

Şekil 4. Son 8 y1llık dönemde y1llık halka genișliklerindeki değișim. Olay 2012 y1lı başında gerçekleştiğinden 2012 y1lı halkası da normalden çok daha geniştir ve bu ani değişim olayın gerçekleştiği yılı ve yıl içindeki dönemi verebilmektedir.
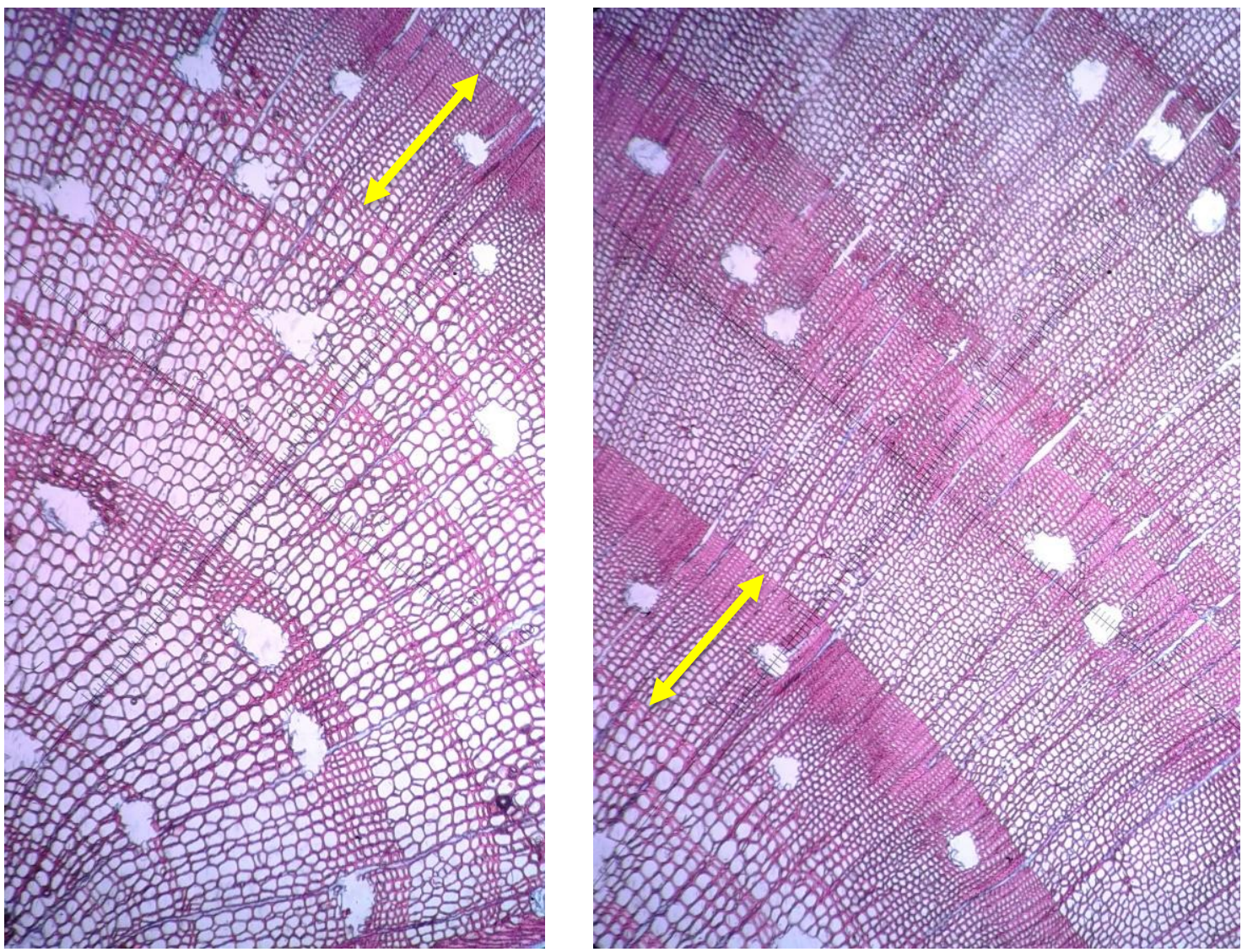

Şekil 5 a ve b. Heyelanın kök anatomisi üzerine etkisi. Yıllık halka genişliği, traheid çapı ve yaz odunu oranındaki değişim (Çift başlı ok heyelan yılını (2012) göstermektedir. Okun işaret ettiği mesafe 1.8 mm'dir). 
Heyelanın kök anatomisi üzerine etkisi, 2012 y1lından itibaren belirgin şekilde azalan traheid çapları, genişleyen yıllık halkalar ve artan yaz odunu oranları şeklinde görsel olarak da izlenmektedir (Şekil 5a ve 5b). Heyelan etkisiyle y1lllık halka anatomisinde meydana gelen değişimi incelemek için alınan mikroskobik kesitlerde görüldüğü üzere, heyelan sonrası traheid hücrelerinin radyal çaplarında \% 44.5 oranında daralma meydana gelmiştir. Heyelan y1lı (2012) öncesindeki y1llk halkalarda ortalama traheid radyal çap1 $66.09 \pm 5.31 \mu \mathrm{m}$ iken, heyelan sonras1 dönemde bu değer $29.47 \pm 3.10 \mu$ m'dir.
İncelenen kök sektöründe traheid radyal çapının son sekiz yıldaki (2008-2105) değişimi Şekil 6'deki grafikte verilmiştir. Grafikte heyelanın kök anatomisi üzerindeki etkisi açık biçimde görülmektedir.

Diğer taraftan incelenen kök enine kesitinin bazı kısımlarında 2012 y1lı ile birlikte dişli yıllık halka (indented ring) oluşumu tespit edilmiştir (Şekil 3 ve 7). Heyelanın neden olduğu mikro-yaralarla bağlantılı olarak dişli yıllık halka oluşumunun da heyelanın gerçekleştiği yıla işaret edebileceği bu çalışma ile gösterilmiştir.

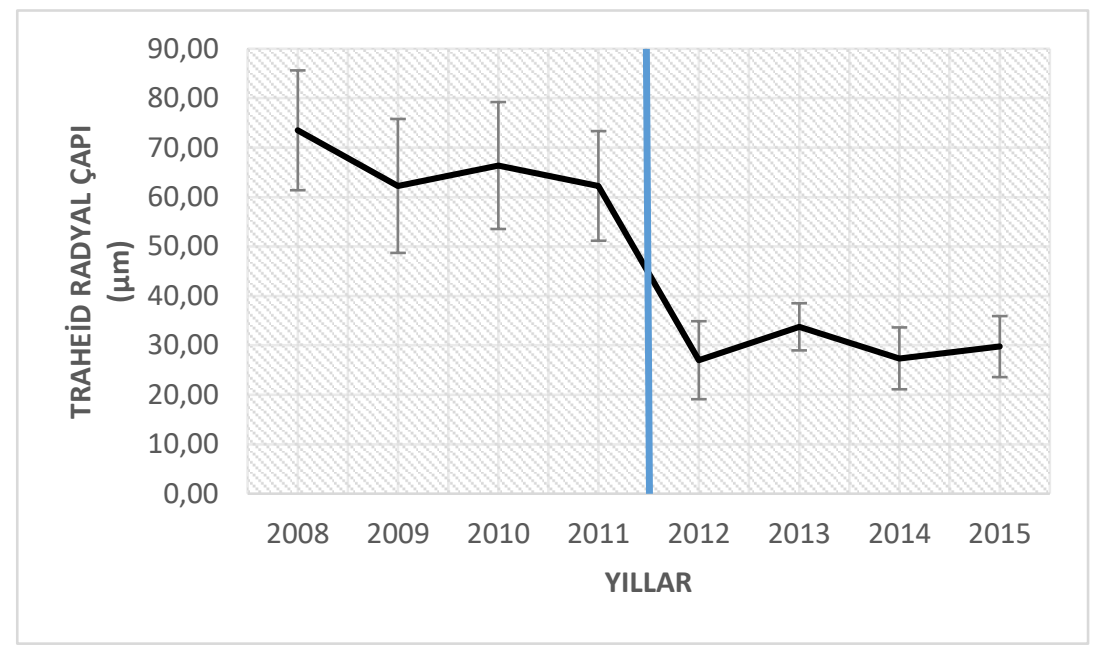

Şekil 6. Traheid radyal çapının heyelan nedeniyle değişimi

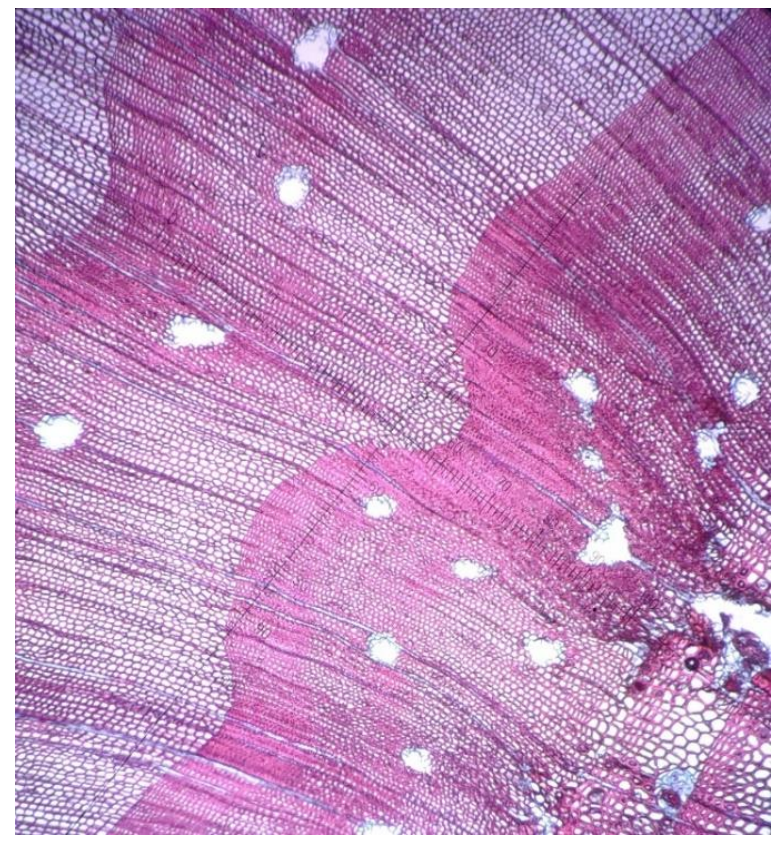

Şekil 7. Heyelan sonrası, mikro-yara bölgesinin devamı olarak dişli yıllık halka (indented ring) oluşumu. 


\section{Tartışma ve Sonuç}

Heyelan sonrasında toprak yüzeyine çıkan karaçam ağacının kökü, heyelan etkisini belirgin şekilde ortaya koymuştur. $\mathrm{Bu}$ bağlamda;

a. Y1llık halka genişliği heyelan sonrasında artmıştır. Heyelan öncesi dar olan y1llık halkalar, heyelan sonrasinda artan vaskular kambiyum faaliyetine bağlı olarak çok belirgin olarak genişlemiştir. Çeşitli jeomorfolojik hareketlerle açığa çıkan kök odunlarında olay sonrası kök odunu yıllık halka genişliğinde artış olduğu başka araștırmalarda da belirtilmiștir (Gaertner ve ark., 2001; Bodoque ve ark., 2005; Gaertner 2007; Rubiales ve ark., 2008; Stoffel ve Bollschweiler, 2008 ve 2009). Çalışmamız benzer bir sonucu ortaya koymuştur.

b. Heyelan sonrasinda artan yıllık halka genişliğine bağlı olarak yaz odunu oranı da artmıştır. Özellikle heyelan öncesinde çok düşük oranda (1-3 sıra traheid hücresi) olan yaz odunu, ani bir artışla oldukça genişlemiştir. Böylece kök odunu özelliğinden hızlı bir şekilde gövde odununa benzer bir yapıya dönüşüm meydana gelmiştir. Gaertner ve ark. (2001), Gaertner (2007) ve Rubiales ve ark. (2008) da inceledikleri jeomorfolojik olaya bağlı olarak benzer bir sonuca işaret etmektedir.

c. Y1llık halka genişliğinin tersine, traheid çaplarının heyelan sonrasında \% 44.5 oranında daraldığı tespit edilmiştir. Bu sonuç Gaertner ve ark. (2001), Gaertner (2007) ve Rubiales ve ark. (2008)'da verilen değerlerle oldukça uyumludur.

d. Heyelan nedeniyle kökte oluşan mikroyaralara bağlı olarak heyelan sonrası dişli y1llkk halka (indented ring) oluşumu ortaya çıkabilmektedir. Dişli yıllık halka oluşumunun başladığı yıl da jeomorfolojik olayın meydana geldiği yıla işaret edebilmektedir.

Sonuçlar, meydana gelen bir heyelan olayının ağaç kökü üzerindeki etkisini belirgin şekilde göstermiştir. Çalışılan örnekte, yıllık halka genişliği, yıllık halkadaki yaz odunu oranının artması ve traheid çaplarının daralması şeklinde ortaya çıkan etki, olaya karşı vaskular kambiyum tarafindan verilen belirgin bir tepkidir. $\mathrm{Bu}$ tepkiye dayanarak heyelan, enkaz akışları, kaya ve taş yuvarlanmaları, sel, çı̆̆ gibi çeşitli jeomorfolojik olayların ağaç köklerindeki etkilerini incelemek ve böylece tarihi bilinmeyen jeomorfolojik olayları tarihlendirmek mümkün olmaktadır. $\mathrm{Bu}$ türden çalışmalarla, yukarıda değinildiği şekilde, jeomorfolojik olayların incelenmesi yanısıra, çeşitli orman suçlarının aydınlatılması (Yaman ve Akkemik, 2009), ağaç gelişimi ve büyümesi gibi olayların dinamiğinin anlaşılması da mümkün olacaktır. Türkiye bu türden çalışmalar için oldukça bakir olup konuyla ilgili araştırmalar yok denecek kadar az sayıdadır.

*Not: Bu makale içeriğinin bir bölümü, T.C. Orman ve Su İşleri Bakanlığı Çölleşme ve Erozyonla Mücadele Genel Müdürlüğü tarafindan 27-29 Nisan 2016 tarihinde Ankara'da düzenlenen Ulusal Heyelan Sempozyumunda sözlü bildiri olarak sunulmuştur.

\section{Kaynaklar}

Akkemik Ü. 2004. Dendrokronoloji: İlkeleri, Biyolojik Temelleri, Yöntemleri, Uygulama Alanları. ISBN: 975-404-730-8, 260s, İstanbul Üniversitesi Orman Fakültesi Yayını, İstanbul.

Avcı M. 2007. Coğrafyacılar için Dendrokronoloji. ISBN: 978-975-9060-43-5, 247s, Çantay Yayınları, İstanbul.

Aytuğ B. 1984. Sülük Gölü'nün Oluşumu, TUBİTAK Arkeometri Ünitesi bilimsel toplantı bildirileri IV, Ankara.

Aytuğ B., Kılıç A. 1993. Contribution D'une Étude Dendrochronologique Á La Constatation De L'áge Du Lac Sülük (Bolu), Proceeding 5th Optima Meeting, Istanbul 8-15 September, 1986: 119-233, İstanbul.

Bodoque J.M., Diez-Herrero A., Martin-Duque J.F., Rubiales J.M., Godfrey A., Pedraza J., Carrasco R.M., Sanz M.A. 2005. Sheet erosion rates determined by using dendrogeomorphological analysis of exposed tree roots: two examples from Central Spain. Catena 64: 81-102.

Butler D.R., Malanson G.P., Oelfke, J.K. 1987. Tree-ring analysis and natural hazard chronologies: Minimum sample sized and index values. Professional Geographer 39(1): 41-47.

Clague J.J. 2010. Dating landslides with trees. (Eds. M. Stoffel, M. Bollschweiler, D.R. Butler, B.H. Lokman, Tree Rings and Natural Hazards: A State-of-the-Art). 81-89, Springer, Dordrecht, Heidelberg, London, New York.
EM-DAT
(2016)
The OFDA/CRED

International Disaster Database. Université 
Catholique de Louvain, Brussels, Belgium. Available at www.emdat.be.

Ercanoğlu M., Gokceoğlu C., Van Asch Th.W.J. 2004. Landslide susceptibility zoning north of Yenice (NW Turkey) by multivariate statistical techniques. Nat Hazards 32: 1-23.

Ercanoğlu M. 2005. Landslide susceptibility assessment of SE Bartin (West Black Sea region, Turkey) by artificial neural networks. Nat Hazards Earth Syst Sci 5: 979-992.

Gaertner H., Schweingruber F.H., Dikau R. 2001. Determination of erosion rates by analyzing structural changes in the growth pattern of exposed roots. Dendrochronologia 19: 1-11.

Gaertner H. 2007. Tree roots-Methodological review and new development in dating and quantifying erosive processes. Geomorphology 86: 243-251.

Gaertner H., Schweingruber, F. H. 2013. Microscopic Preparation Techniques for Plant Stem Analysis. ISBN: 978-3-941300-76-7, 78p. Verlag Dr Kessel, Remagen.

IAWA Committee 2004. IAWA list of microscopic features for softwood identification. IAWA J. 25: 1-70.

Malik I., Wistuba M. 2012. Dendrochronological methods for reconstructing mass movements - An example of landslide activity analysis using tree-ring eccentricity. Geochronometria 39 (3): 180-196.

Pınarc1 E., Çetin H. 2012. Haç gediği heyalanının (Karaisalı/Adana) ağaç halkaları yöntemiyle analizi. Ç.Ü Fen ve Mühendislik Bilimleri Dergisi, 27 (1): 130-141.

Rubiales J.M., Bodoque J.M., Ballesteros J.A., Diez-Herrero A. 2008. Response of Pinus sylvestris roots to sheet-erosion exposure: an anatomical approach Nat. Hazards Earth Syst. Sci., 8: 223-231.
Schweingruber F.H. 1989. Tree rings - Basics and applications of dendrochronology. ISBN: 90277-2445-8, 276p. Kluwer Academic Publishers, Dordrecht, Holland.

Schweingruber FH. 2007. Wood Structure and Environment. IBN: 978-3-540-48299-4, 279 p., Springer-Verlag, Berlin, Heidelberg.

Stoffel M., Bollshweiller M. 2008. Tree-ring analysis in natural hazards research-an overview. Nat Hazards Eart Sys Sci 8: 187-202.

Stoffel M., Bollchweiller M. 2009. What tree rings can tell about earth-surface processes: teaching the principles of dendrogeomorphology. Geography Compass 3 (3): 1013-1037.

Wilford D.J., Cherubini P., Sakals M.E. 2005. Dendroecology: a guide for using trees to date geomorphic and hydrologic events. B.C. Min. For., Res. Br., Victoria, B.C. Land Manage. Handbook No. 58.

Wistuba M., Malik I., Owczarek P. 2011. Eccentric growth of trees as a tool for reconstruction of mass movement activity (example from the Carpathian Mountains-Central Europe). (Eds. Maaten-Theunissen M., Spiecker H., Gärtner H., Helle G., Heinrich I., TRACE-Tree Rings in Archaeology, Climatology and Ecology), Vol. 9. GFZ Potsdam, Scientific Technical Report STR 11/07, Potsdam, p. 103-108.

Yaman B., Akkemik Ü. 2009. The use of dendrochronological method in dating of illegal tree cuttings in Turkey: a case study. Baltic Forestry. 15(1): p. 122-126.

Yaman B., Köse N., Akkemik Ü. 2013. Changes in stem growth rates and root wood anatomy of oriental beech after a landslide event in Hanyeri, Bartın, Turkey. Turkish Journal of Agriculture and Forestry, 37: 105-109. 